dramatic manner in which Kenjira Ota arrived upon the scene of his labors, pages 148-150, to find him accomplishing nothing more remarkable than the measurement of the freezing points of certain solutions.

In view of the fact that none of the author's own investigations have been in the field of radioactivity, it seems rather remarkable that the references, pages 260, 261 and 296, to the author's book on the "Electrical Nature of Matter and Radioactivity" are not supplemented by the titles of well-known standard works on the subject.

However, the reviewer does not wish to be understood as wholly condemning the book. Far from it. The idea of writing a book on a "New Era in Chemistry" is an excellent one, and the story, for the most part, is most interestingly told, but at the same time it is the reviewer's conviction that no one who permits so many inaccurate, careless and exaggerated statements to creep into his work should go unrebuked.

The book closes with an appendix in which are given some delightful personal reminiscences of the great men who made possible the "New Era in Chemistry."

\section{Edward C. FrankLin}

\section{Rays of Positive Electricity and their Applica-} tion to Chemical Analysis. By SIR J. J. Thomson. Longmans, Green \& Co. 1913. Pp. vi +132 . Price, $\$ 1.40$.

The day of the monograph in physics is apparently here, and it will be hailed with delight not only by physicists, but also by workers in all of the neighboring sciences. For in a period like the present in which new material is appearing very rapidly, and in which the "accumulation time" of new viewpoints is extraordinarily short, it is of the utmost importance that the results of recent research be got as quickly as possible in some form which is intermediate between the journal article, with its inaccessibility and incompleteness, and the general treatise with its rigidity and inertia. Monographs of the sort which Longmans has announced, dealing with half a dozen of the more recently developed departments of physics and written by men who have been prominently identified with their development, will appeal to a wide audience.

And if the whole Longmans series is as good as the first number, the publishers, the authors, the editors and the public may all congratulate themselves. For Sir J. J. Thomson has done his very best work, so it seems to the reviewer, on positive rays, and the present monograph is a fascinatingly simple and straightforward account of that work, introduced by a discussion of the preceding work of Goldstein and of Wien, and supplemented by a chapter on the Döppler effect with positive rays, discovered and investigated chiefly by Stark and his pupils. If any one has had doubt about the effectiveness of the positiveray method as a means of discovering the sorts of atoms and molecules which constitute the residual gases in discharge tubes, and the values of the electrical charges carried by these atoms and molecules, he should take enough time to study carefully the five plates of actual photographs contained in this book. The parabolas shown in these photographs are about as convincing evidence as could be desired.

\section{R. A. Millikikan}

\section{SPECIAL ARTICLES}

DESICCATION OF CERTAIN GREGARINE CYSTS

Is connection with other studies on the cephaline gregarine Stylocephalus giganteus Ellis some data have been collected during the past fall concerning the viability of the cysts of this sporozoon and the effect of dryness on the formation of sporocysts. This gregarine is a common parasite in the alimentary canal of the Tenebrionid beetles of the genera Eleodes and $A$ sida, so abundant in the semi-arid plains of eastern Colorado.

The cysts of Stylocephalus giganteus are subspherical, about 450 microns in diameter and opaque white when first discharged from the host. Unlike the cysts of many species of gregarines, they are not provided with thick, gelatinous envelopes, their walls on the contrary, are quite thin, the gelatinous envelope 
if present at all being reduced to a thin film. If placed in water immediately after being discharged from the host, the cysts remain unchanged in external appearance for 4 days or more. After about 5 days the formation of sporocysts has progressed to such an extent that the cysts begin to turn gray, changing gradually to jet black in the next 2 or 3 days. Shortly after reaching the jet-black stage the cysts dehisce by simple rupture, discharging the long chains of ovoid sporocysts. Ten days usually elapsed between the time the cyst left the host and dehiscence, and no cyst examined dehisced in less than 8 days.

By starving the hosts it was found that the cysts were discharged in numbers almost free from excrement, and that such fluid excrement as did accompany the cysts dried rapidly, leaving the naked cysts glued to the glass tubes in which the hosts were confined. On September 23, 1913, several Eleodes sp. which had been starved for five days were placed in clean test tubes and over fifty cysts collected. The fluid excrement surrounding these dried in less than three hours, leaving the naked cysts adhering to the walls of the tubes. The beetles were removed and the tubes loosely plugged with cheese cloth. After plugging the tubes they were returned to the rack and allowed to remain undisturbed for 138 days. During this time they were in the light that came in through a north window, but not in direct sunlight, and were subjected to severe drying, as the room in which they were kept was heated with dry air, which together with the naturally dry air of Colorado dehydrated the cysts to such an extent that they shriveled and fell to the bottom of the tubes. On January 23, 1914, such cysts as had fallen to the bottoms of the tubes were removed and examined. All were still white, showing that the last stages of sporocyst formation had not been reached, and all were much shriveled and wrinkled, being reduced to half or less of their original volume. The dry cysts were then placed in water and after twenty-four hours' soaking they resumed their original spherical shape, still remaining white. By the end of the second twenty-four hours in water they had turned dark gray, and on the third day all were jet black, some having dehisced the long chains of ovoid sporocysts. From the time of discharge from the host to dehiscence these cysts were in fluid excrement for less than three hours, in dry air for 138 days and in water for less than three days. During the period of drying they did not lose their vitality and sporocyst formation was not completed. That internal changes had taken place in spite of the dry air is suggested by the rapid completion of sporocyst formation when the cysts were placed in water, dehiscence taking place in three days as compared with maturation period of ten days required by cysts taken directly from fresh excrement and placed in water.

This ability of the cysts of Stylocephalus giganteus to withstand a certain desiccation is perhaps an important factor in the distribution of this parasite which is so generally successful in eastern Colorado. Two stages at least, the cyst and the sporocyst, and possibly a third, the sporozoite, must be considered as distributional stages, comparable to some extent to those stages of many parasites which are passed in the secondary hosts. Each cyst of Stylocephalus giganteus produces an enormous number of sporocysts, which, as in most species of gregarines, are well protected by tough coats, and from the standpoint of species distribution both the number of sporocysts and their tough, protective coats are presumably positive factors in increasing the chances of this species being taken into the alimentary canal of many hosts. If the cyst be destroyed the type of sporocyst is of no importance, and cysts are produced in relatively small numbers, since each represents a fusion of two adult gregarines. It is then essential to the gregarine species that the cyst be able to withstand the unfavorable conditions of the environment in the habitat of the host species until sporocysts may be formed. This is accomplished in some species as Gregarina blattarum Siebold of the cockroach and Gregarina rigida (Hall) of various species of grasshoppers, by the thick gelatinous envelope surrounding the cyst. This envelope when 
dried forms a very tough coat for the cyst. In the case of Stylocephalus giganteus it seems that the physiological character which makes the cyst resistant to desiccation, even though dehydration proceed to the distortion of the cyst, is of value to this species in much the same way as the protective envelopes of the first two species. The host of Stylocephalus giganteus is active throughout the winter on warm days, so that this species does not have to overcome the loss of host during the winter months as does Gregarina rigida in the grasshopper, and Eleodes sp. have been taken in December and January containing as many gregarines as beetles of the same species taken in August. These beetles are however dis-

\section{SEMI-PERMEABLE CAPSULES}

During a series of experiments to determine the permanency of the fermentative reactions of intestinal bacteria in stored waters, it became necessary to use semi-permeable capsules. A review of the literature failed to show any method which was suitable for our purpose.

As in McCrae's work, gelatine capsules (size 00) are used as a basis for the colloidin capsule. A glass tube about $15 \mathrm{~cm}$. in length is warmed in the gas flame and pressed into the closed end of the empty gelatine capsule. The gelatine plug which inevitably forms in the glass tube must be removed, at this point by means of a wire, otherwise ruptures are

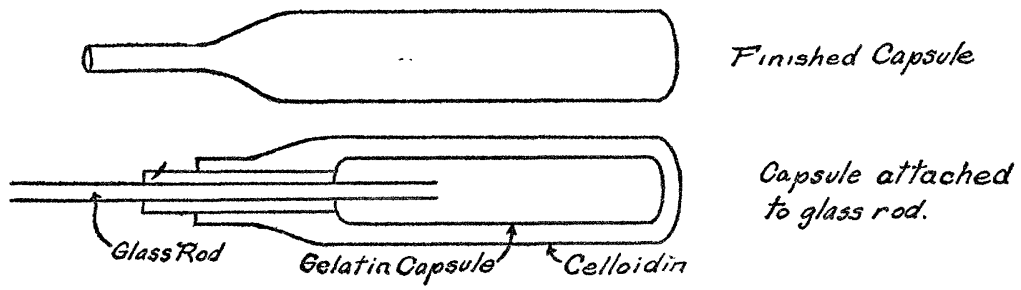

FIG. 1.

tributed through a semi-arid region and the favorite habitats of Eleodes spp., under stones or at the bases of shrubby plains plants, are quite dry for the greater part of the year, subjecting the cysts of Stylocephalus giganteus even though protected to some extent by the excrement of the host, to considerable drying. As shown by the cysts under observation. moisture is essential to the completion of sporocyst formation, since the cysts kept in dry air did not reach the gray and black stages until after they were placed in water. By examination of the meteorological data for eastern Colorado it may be seen that the period of drying to which the cysts here considered were subjected, over four months, exceeds the average droughts in this part of the plains where Eleodes spp. are so extensively parasitized.

\section{UNIVERSITY OF COLORADO}

liable to occur when the capsules are boiled later.

The union of the capsule and the glass rod is made airtight by coating the union with a twenty per cent. solution of gelatine by means of a small brush. The layer of gelatine is extended up the glass tube for a distance of about $4 \mathrm{~cm}$. If the two halves of the capsule do not fit tightly, it is advisable to paint them also with the gelatine.

After thoroughly drying, the capsule is dipped into the colloidin solution (colloidin 1 part, ether $1 \frac{1}{2}$ parts and alcohol $1 \frac{1}{2}$ ) until a proper thickness is attained, which may be judged by holding the capsule before the light. Experience has shown that at least four dippings are necessary. It was found that the finished capsules were often weak at the point where the halves of the gelatine capsule meet. This point was strengthened by allowing additional colloidin to collect at this place. The 